\title{
Growth performance and sorting characteristics of corn silage-alfalfa haylage diets with or without forage dilution offered to replacement Holstein dairy heifers ${ }^{1}$
}

\author{
W. K. Coblentz, $\dagger^{2}$ N. M. Esser, $\ddagger$ P. C. Hoffman, $\S$ and M. S. Akins \\ †USDA-ARS, US Dairy Forage Research Center, Marshfield, WI 54449 \\ \#University of Wisconsin Marshfield Agricultural Research Station, Marshfield 54449 \\ §Department of Dairy Science, University of Wisconsin, Madison 53706
}

\begin{abstract}
Gravid heifers consuming high-quality forage diets are susceptible to excessive weight gains and overconditioning. One approach for controlling this problem is to dilute diets with low-energy forages, such as straw, that reduce the caloric density and dry matter intake (DMI) of that diet by heifers. These diluting agents are often sortable by dairy heifers, but previous visual evidence has suggested that eastern gamagrass haylage may be a nonsortable alternative. Our objectives were (1) to compare the growth performance of dairy heifers offered a high-quality forage diet (control) with diets containing 1 of 3 diluting agents [eastern gamagrass haylage (EGH), chopped wheat straw (WS), or chopped corn fodder $(\mathrm{CF})]$; and (2) evaluate sorting behaviors of heifers offered these forage diets. Holstein heifers (n $=128$ ) were stratified ( 32 heifers/block) on the basis of initial body weight (heavy, $560 \pm 27.7 \mathrm{~kg}$; mediumheavy, $481 \pm 17.7 \mathrm{~kg}$; medium-light, $441 \pm 22.0 \mathrm{~kg}$; and light, $399 \pm 14.4 \mathrm{~kg}$ ), and then assigned to 1 of 16 identical research pens (4 pens/block; 8 heifers/pen), where each of the 4 research diets were assigned to 1 pen within each block. Diets were offered in a 118-d feeding trial with heifers crowded to $133 \%$ of capacity at the feed bunk. Inclusion of low-energy forages was effective in reducing both diet energy density and DMI. Concentrations of physically effective fiber ( $p e f$ ) particles did not change during the 24-h period following feeding for either the control or EGH diets; however, this response for pef particles masked the competing (and cancelling) responses for individual large and medium particles, which heifers sorted with discrimination and preference, respectively. Sorting against pef

\footnotetext{
Received February 20, 2015.

Accepted July 5, 2015.

${ }^{1}$ Mention of trade names or commercial products in this article is

${ }^{2}$ Corresponding author: wayne.coblentz@ars.usda.gov
} solely for the purpose of providing specific information, and does not imply either recommendation or endorsement by the USDA.
\end{abstract}

particles was detected for WS, and much more severely for the CF diet. Sorting of forage particles by heifers could not be related to heifer performance. Compared with control $(1.16 \mathrm{~kg} / \mathrm{d})$, average daily gains (ADG) were reduced by dilution in all cases, but were virtually identical between EGH $(0.98 \mathrm{~kg} / \mathrm{d})$ and $\mathrm{CF}(0.97$ $\mathrm{kg} / \mathrm{d}$ ), which exhibited no sorting and extensive sorting of pef, respectively. Furthermore, ADG for WS was approximately $0.2 \mathrm{~kg} / \mathrm{d}$ less than EGH or $\mathrm{CF}$, despite exhibiting sorting characteristics intermediate between EGH and CF. Diets diluted with low-energy forages were formulated to be isonitrogenous and isocaloric; within that context, WS was most effective in reducing DMI and maintaining ADG within typical recommendations for Holstein heifers.

Key words: dairy heifer, dry matter intake, energy dilution, sorting

\section{INTRODUCTION}

Management programs for dairy replacement heifers seek to rear animals at a low economic and environmental cost without compromising their future performance as lactating cows (Hoffman et al., 2007). Generally, diets for replacement dairy heifers are forage based, but those containing significant proportions of corn silage or other high-quality forages can be problematic because they are energy dense and often exceed the energy requirements for growing dairy heifers. Such diets also may contain inadequate NDF to restrict DMI via the gut-fill mechanism. Intensive evaluation of typical dairy-heifer diets offered in confinement has indicated that dairy heifers consume approximately $1.0 \%$ of their BW daily as NDF (Hoffman et al., 2008). Therefore, heifers consuming high-quality forage diets with low NDF concentrations are susceptible to excessive DMI, and subsequently, increased weight gains and overconditioning. This can be associated with various deleterious effects on mammary development and subsequent first lactation performance (Sejrsen et al., 1982; Hoffman et al., 1996; Lammers et al., 1999; Radcliff et al., 
2000), although Van Amburgh et al. (1998) concluded that prepubertal BW gains ranging from 0.5 to 1.1 $\mathrm{kg} / \mathrm{d}$ explained only a small portion of the variation in milk yield. To control this problem, 2 general management approaches have been used to limit caloric intake within dairy heifers: (1) dilution of the ad libitum diet with low-energy forages, such as straw (Hoffman et al., 1996; Greter et al., 2008); or (2) offering a diet of greater energy concentration, but the amount of feed available for consumption is deliberately restricted to limit caloric intake such that energy requirements for acceptable weight gains are met without undesirable overconditioning (limit-feeding; Hoffman et al., 2007; Zanton and Heinrichs, 2007; Zanton and Heinrichs, 2008; Kruse et al., 2010).

Specific benefits of ad libitum feeding programs containing diluting agents have been noted, and include (1) potentially reducing feed costs, (2) allowing targeting of caloric intake to meet specific producer goals for weight gain and development, and (3) providing heifers with opportunities for expression of natural foraging behaviors (Greter et al., 2008). Another advantage of ad libitum feeding programs for heifers is that overcrowding of facilities is possible because feed is always available for passive heifers to eat. Limit-fed heifers have exhibited improved feed efficiency and reduced fecal output compared with heifers offered diets for ad libitum intake (Hoffman et al., 2007; Kruse et al., 2010; Coblentz et al., 2013). Both of these management options also have known limitations. Hoffman et al. (2007) noted increased time standing (without eating), as well as increased vocalization by limit-fed heifers; increased standing time is potentially problematic because it has been associated with hoof disease in lactating cows (Cook et al., 2004). Ad libitum diets containing straw or other low-energy diluting agents often are actively sorted by heifers, resulting in discrimination against long forage particles, including those from chopped straw (Greter et al., 2008). Potentially, these sorting behaviors may cause heifers or lactating cows to consume unbalanced diets, and possibly incur acidosis (DeVries et al., 2008). Furthermore, these risks may be exacerbated by overcrowding, especially when coupled with the wide range of aggressive and passive behaviors exhibited within any pen of heifers. Inadequate bunk space has been observed to increase day-to-day variations in feeding behavior (DeVries and von Keyserlingk, 2009), as well as within-pen variability with respect to daily weight gains by heifers (Longenbach et al., 1999).

Recently, eastern gamagrass [Tripsacum dactyloides (L.) L.] haylage has been used successfully to control weight gains of replacement dairy heifers offered blended corn silage/alfalfa (Medicago sativa L.) haylage diets that supported excessive ADG without dilution (Co- blentz et al., 2012). These responses were accomplished primarily by direct substitution for corn silage, and reduced weight gains were facilitated by (both) reducing the caloric density of the diet, as well as restricting DMI via the gut-fill mechanism. Eastern gamagrass possesses the $\mathrm{C} 4$ photosynthetic pathway (Waller and Lewis, 1979), and is a perennial bunch-type grass that is a distant relative of corn (Bates et al., 1981). Research conducted in central Wisconsin has verified that this perennial warm-season grass can survive winter climatic conditions throughout the region, and will produce yields of DM ranging generally from 7,000 to $10,000 \mathrm{~kg} /$ ha by mid-August using a 1 -cut harvest system (Coblentz et al., 2010a), although more recent work (Coblentz et al., 2014) has shown that yields from 1-cut harvest systems are likely maximized during midto-late September. Furthermore, concentrations of NDF in eastern gamagrass forages harvested during this time period range generally from 75 to $80 \%$ (Coblentz et al., 2010b, 2014). An intriguing observation made during the previous feeding trial with this forage was that heifers did not exhibit the undesirable sorting behaviors that typically are observed when chopped straw is used to dilute heifer diets (Coblentz et al., 2012). Our objectives were (1) to compare the growth performance of dairy heifers offered a corn silage/alfalfa haylage diet (control) with diets containing 1 of 3 diluting agents [eastern gamagrass haylage, chopped wheat (Triticum aestivum L.) straw, or chopped corn (Zea mays L.) fodder]; and (2) evaluate sorting behaviors of heifers offered these blended forage diets.

\section{MATERIALS AND METHODS}

\section{Forages}

'Pete' eastern gamagrass was established at the University of Wisconsin Marshfield Agricultural Research Station located near Stratford, Wisconsin $\left(44^{\circ} 7^{\prime} \mathrm{N}\right.$, $\left.90^{\circ} 1^{\prime} \mathrm{W}\right)$ on May 6, 2009, with a John Deere 4-row planter (model 7000, Deere and Co., Moline, IL) at an approximate seeding rate of 138,600 seeds $/ \mathrm{ha}(9 \mathrm{~kg} / \mathrm{ha})$; other details related to establishment, maintenance, and harvest of eastern gamagrass have been described previously (Coblentz et al., 2012). Large-square bales $(0.9 \times 0.9 \times 2.1-\mathrm{m})$ of wheat straw were purchased locally, and then ground through a Haybuster Model 1100 tub grinder (DuraTech Industries International Inc., Jamestown, ND) equipped with a 10.2-cm screen. Corn fodder was obtained during the harvest of highmoisture corn by using a model 7130 combine (CaseInternational Harvester; CNH Industrial, Racine, WI) equipped with a model 4408 fodder chopping head, raking the discharged chopped corn fodder into rows with 
a side-delivery rake, and then precision-chopping the raked fodder (11.1-mm; 7/16-inch theoretical length of cut) with a forage harvester (model FX300, CaseInternational Harvester). Alfalfa haylage, corn silage, eastern gamagrass haylage, and corn fodder were all ensiled in 3.0-m diameter plastic silo bags located in the research station (Kelly Ryan Equipment Company, Blair, NE).

\section{Animals, Housing, and Diets}

All animal handling procedures for this experiment were approved by the Research Animal Resources Committee of the University of Wisconsin-Madison (protocol \#A01541). One hundred twenty-eight Holstein heifers were stratified (32 heifers/block) on the basis of initial BW (heavy, $560 \pm 27.7 \mathrm{~kg}$; medium heavy, $481 \pm 17.7 \mathrm{~kg}$; medium light, $441 \pm 22.0 \mathrm{~kg}$; and light, $399 \pm 14.4 \mathrm{~kg}$ ); heifers were then assigned to 1 of 16 identical research pens (4 pens/block; 8 heifers/pen). Within each pen, heifers had continuous access to fresh water, 8 freestalls with foam-core mattresses bedded with a shallow layer of dried organic solids, an automated mechanical alley-scraping system, and 8 headlocking feeding gates positioned adjacent to a drive-by feed alley. To create competition for feed among heifers, 2 head-locking gates were closed with a plywood partition so that only 6 head-locking gates were available to the heifers, thereby creating overcrowding (133\%) at the feed bunk. Headlocks were set to allow free access and departure from the feed bunk at all times. Experimental diets were dispensed as a TMR (model MW270, Valmetal, St. Germain-de-Grantham, Canada) to each pen once daily between 0900 and $1100 \mathrm{~h}$, and were pushed back within easy reach of the heifers at least twice daily before orts were gathered at $0830 \mathrm{~h}$ the following day.

Each of the 4 research pens within each block was assigned to 1 of 4 experimental diets, with all diets represented within each block. The control diet contained $44.2 \%$ alfalfa haylage and $55.8 \%$ corn silage (Table 1), which are the 2 most commonly available forages throughout the region, and was formulated specifically as a negative control. This approach was used for 2 reasons: (1) to illustrate the common management problem of heifer diets containing too much corn silage or other high-quality feedstuffs, and (2) to establish a baseline from which the effectiveness of diluting agents could be assessed. The remaining 3 diets (Table 1) all included the identical base forages represented within control, but each was diluted with low-energy forage that was primarily substituted for corn silage [eastern gamagrass haylage (EGH), chopped wheat straw (WS), or chopped corn fodder (CF)]. All diets were isonitrogenous (overall mean $=13.8 \% \mathrm{CP}$ ); in addition, the diluted diets were isocaloric (overall mean $=$ $59.2 \%$ TDN), which was reduced by $11 \%$ relative to control $(66.8 \%)$. Our initial hypothesis was that heifers would exhibit different sorting behaviors based on which diluting agent was added to the diet; generally, we postulated that EGH would be largely nonsortable, whereas WS would represent the industry standard and be moderately sortable, and the CF diet was assumed to be highly sortable.

Each of the 4 experimental diets were offered for ad libitum intakes for $118 \mathrm{~d}$, but were managed to a defined bunk score of 2 , where $0=$ no feed particles remaining, 1 = only scattered feed particles remaining, 2 $=$ numerous particles remaining, but the concrete floor is still easily visible, or $3=$ feed particles completely covering the concrete bunk floor (Hoffman et al., 2008). Bunks were scored each morning, and the amount of TMR was adjusted daily on this basis to maintain the pre-established bunk score of 2; normally, a bunk score of 0 triggered a $6 \%$ increase in the daily diet allocation calculated on an as-is basis, whereas bunk scores of 1 and 3 triggered a $3 \%$ increase and decrease, respectively. Samples of each diet were obtained daily, frozen $\left(-20^{\circ} \mathrm{C}\right)$, and composited by week for analysis. Each morning, orts were swept from each feed bunk, weighed in a large (tared) plastic tub, subsampled, frozen $\left(-20^{\circ} \mathrm{C}\right)$, and then composited by week. A $400-\mathrm{g}$ subsample of the weekly diet and ort composites was dried to constant weight under forced air at $55^{\circ} \mathrm{C}$ to determine the concentration of DM within these weekly composite samples.

\section{Feed Bunk Sampling Procedures}

To assess heifer feed sorting and eating behaviors, feed bunks were sampled across 4 evaluation periods that occurred during wk $6,8,12$, and 16 of the trial; each evaluation period was $5 \mathrm{~d}$ in length. Following discharge of the TMR between 0900 and $1100 \mathrm{~h}$ each morning, subsequent feed-bunk sampling times were scheduled at 1300,1700, 2100, 0100, and $0600 \mathrm{~h}$. To minimize the disruption of eating and sorting behaviors, feed bunks were sampled only once daily. Sampling times were randomized for each pen across the 5-d period, such that each sampling time was represented on $1 \mathrm{~d}$ of the 5 - $\mathrm{d}$ period. To obtain a sample, the length of the feed bunk was arbitrarily divided in half; within each half, a scoop shovel was used to remove all the feed within the width of the shovel from the feed alley to the concrete curb on which the locking head gates were mounted. An identical procedure was used for the other half of the feed bunk. These large samples were composited and thoroughly mixed within 
a large plastic tub. From the mixed contents of the tub, a subsample $(\sim 1,000 \mathrm{~g})$ was sealed in a 3.8 -L freezer bag and frozen $\left(-20^{\circ} \mathrm{C}\right)$ pending subsequent evaluation of particle size and nutritive value. During each experimental period, 1,000-g samples also were obtained from all individual dietary components (alfalfa haylage, corn silage, chopped wheat straw, eastern gamagrass haylage, and chopped corn fodder) for evaluation of particle size distribution. In addition, samples of the experimental diets (control, EGH, WS, and CF) and orts collected from each pen were obtained from the regular weekly sampling procedures described previously. Samples of dietary components, diets, and orts also were frozen $\left(-20^{\circ} \mathrm{C}\right)$ in 3.8 -L freezer bags pending subsequent particle-size distribution analysis.

To provide supporting information describing heifer behavior, simple counts were taken of various heifer activities within each research pen at each feed-bunk sampling time. Six activity categories were used: (1) eating, (2) lying in freestalls, (3) actively refused from eating by dominant or aggressive heifers, (4) standing with at least 2 feet in the freestall (perching), (5) inactive standing, or (6) other activities, which consisted primarily of drinking, or (occasionally) estrus. Counts were made for each research pen during all days of the 4 evaluation periods; therefore, the mean response for

Table 1. Ingredient composition of experimental diets, and mean nutrient composition of blended diets and individual dietary components based on weekly analysis (17 wk) by the University of Wisconsin Marshfield Soil and Forage Laboratory (Marshfield, WI)

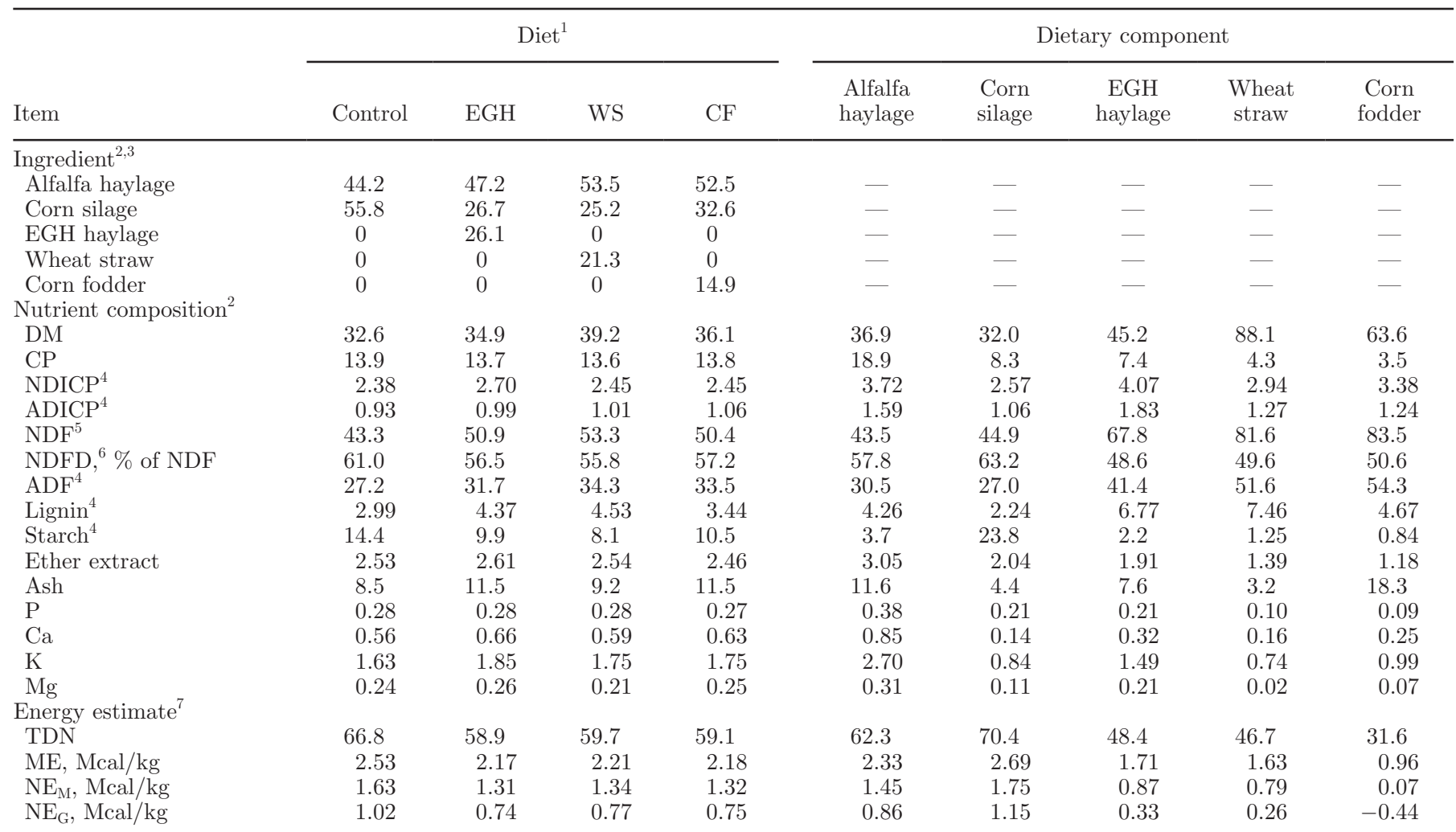

${ }^{1}$ Control = alfalfa haylage/corn silage diet containing no diluting agent and offered for ad libitum intake; EGH = alfalfa haylage/corn silage diet containing $26.1 \%$ eastern gamagrass haylage, and offered for ad libitum intake; WS = alfalfa haylage/corn silage diet containing $21.3 \%$ wheat straw, and offered for ad libitum intake; and CF = alfalfa haylage/corn silage diet containing $14.9 \%$ chopped corn fodder, and offered for ad libitum intake.

${ }^{2}$ All ingredients or nutrients are expressed on a $\%$ of DM basis unless otherwise noted.

${ }^{3}$ Mineral package contained $72.1 \%$ calcium carbonate, $16.5 \%$ salt, $3.35 \%$ sulfur, $2.95 \%$ selenium $1600,1.50 \%$ vitamin A, $0.75 \%$ mineral oil, $0.71 \%$ copper sulfate, $0.69 \%$ vitamin $\mathrm{E}(50 \%), 0.64 \%$ zinc sulfate, $0.51 \%$ vitamin $\mathrm{D}, 0.09 \%$ iodine mix, $0.005 \%$ magnesium sulfate, $0.005 \%$ cobalt carbonate, $0.005 \%$ manganese oxide (60\%), and $0.26 \%$ thiamine. Mineral package was blended into the total diet at a rate of $158 \mathrm{~g} / \mathrm{heifer}$ per $\mathrm{d}$ and delivered as a TMR.

${ }^{4}$ Concentrations of ADF, ADL, starch, neutral detergent insoluble CP (NDICP), and acid detergent insoluble CP (ADICP) were determined for wk $1,4,7,11$, and 16 .

${ }^{5}$ Neutral-detergent solution contained both heat-stable $\alpha$-amylase and sodium sulfite.

${ }^{6} \mathrm{NDF}$ digestibility determined following a 48-h digestion in buffered rumen fluid.

${ }^{7}$ Energy calculations based on NRC (2001). 
each pen for each sampling time was composed of 20 individual observations or counts, whereas the reported diet $\times$ sampling time interactive mean included 80 individual counts.

\section{Laboratory Analysis of Diets}

Weekly diet samples were dried to constant weight under forced air at $55^{\circ} \mathrm{C}$, and then ground through a 1-mm screen in a Thomas Model 4 Wiley Mill (Thomas Scientific, Swedesboro, NJ). Samples then were analyzed by the University of Wisconsin Soil and Forage Laboratory (Marshfield, WI) for (1) CP by a macro-Kjeldahl procedure (AOAC International, 1998; method 988.05); (2) ash by combustion in a muffle furnace at $500^{\circ} \mathrm{C}$ for $6 \mathrm{~h}$; (3) starch (model 2700D, Yellow Springs Instrument Co., Yellow Springs, OH); (4) ether extract (AOAC, 1990; method 920.29); (5) Ca, K, and $\mathrm{Mg}$ by atomic absorption spectroscopy; and (6) P by colorimetric methodology (Schulte et al., 1987). Concentrations of NDF within diet samples were quantified by the methods of Goering and Van Soest (1970) with both heat-stable amylase and sodium sulfite included within the NDF solution. A 48-h in vitro digestion of NDF was conducted in buffered rumen fluid (NDFD) using procedures described in detail by Kruse et al. (2010) and Coblentz et al. (2012). Samples obtained from wk 1, 4, 7, 11, and 16 of the trial also were analyzed for concentrations of ADF and ADL (Goering and Van Soest, 1970) without preliminary digestion in neutral detergent. Concomitantly, independent NDF and $\mathrm{ADF}$ residues also were generated following direct digestion in neutral- or acid-detergent solutions, respectively. Residues were then analyzed for residual $\mathrm{CP}$ (neutral detergent insoluble CP, NDICP, and acid detergent insoluble CP, ADICP, respectively) by the macro-Kjeldahl procedure described previously. For determinations of NDICP, the NDF solution contained heat-stable amylase, but sodium sulfite was omitted to prevent excessive removal of $\mathrm{CP}$ associated with the forage fiber matrix (Van Soest et al., 1991). Calculations of TDN for each diet were made via the summative approach (NRC, 2001) with 48-h NDFD serving as a digestibility coefficient for NDF to estimate truly digestible fiber. Other energy calculations $\left(\mathrm{ME}, \mathrm{NE}_{\mathrm{G}}\right.$, and $\mathrm{NE}_{\mathrm{M}}$ ) were made as defined by NRC (2001).

\section{Calculation of Diet Digestibilities}

Digestibilities of DM, OM, NDF, ADF, hemicellulose, and N (apparent basis) were determined for experimental diets on a whole-pen basis during wk 10, 15, and 17 of the trial. Similar procedures have been used to assess total-tract digestibilities of corn silage-based diets within individual lactating cows (Lee and Hristov, 2013). The concentration of NDF undigested after a 240-h in situ incubation was used as an internal marker to estimate fecal output. At the end of wk 10, 15, and 17, heifers were restrained within head-locking gates at the feed alley, and a $(\sim 100-\mathrm{g})$ fecal sample was collected at approximately $1200 \mathrm{~h}$ from each of the 8 heifers within all pens. Fecal samples were initially frozen $\left(-20^{\circ} \mathrm{C}\right)$, and then thawed and composited by pen $(\sim 30 \mathrm{~g} /$ heifer $)$ for each of the 3 evaluation periods. Pen composites of fecal samples were dried to constant weight under forced air $\left(55^{\circ} \mathrm{C}\right)$, and ground through a $1-\mathrm{mm}$ screen. Weekly composites of diets and orts, as well as ground feces were then sealed in fiber bags (model F57, Ankom Technology Corp., Macedon, NY), and duplicate bags of each $0.25-\mathrm{g}$ sample were incubated in situ for $240 \mathrm{~h}$ within the ventral rumen of 2 nonlactating $(820-\mathrm{kg}$ ) Holstein cows offered a diet of alfalfa haylage $(39.2 \%$ NDF, 21.9\% CP, 64.4\% TDN; University of Wisconsin Soil and Forage Laboratory). Upon removal from the rumen, any remaining cell solubles or microbial debris were removed from the fiber bags with NDF solution using the batch procedures outlined for determination of NDF in an Ankom200 Fiber Analyzer. Both heatstable amylase and sodium sulfite were included in the NDF solution for the termination procedure.

To determine nutrient digestibilities, the diet, ort, and fecal samples that were obtained from each pen were analyzed for fiber components (NDF, ADF, hemicellulose) using sequential procedures described by the manufacturer for an Ankom200 Fiber Analyzer. Concentrations of ash in diet, ort, and fecal samples were determined from $1.0-\mathrm{g}$ subsamples by combustion in a muffle furnace at $500^{\circ} \mathrm{C}$ for $6 \mathrm{~h}$, and $\mathrm{N}$ was determined by a rapid combustion procedure (AOAC International, 1998; method 990.63; Elementar Americas Inc., Mt. Laurel, NJ). All calculations of nutrient digestibilities were based on DMI and orts collected over the entire week (summed over $7 \mathrm{~d}$ ) for each pen. Nutrient digestibilities for each dietary treatment consisted of 12 independent observations ( 3 periods/pen $\times 4$ blocks), where the 3 estimates from each pen were averaged before conducting ANOVA using block as the replication term.

\section{Evaluation of Bunk Samples for Particle Size Distribution and Nutritive Value}

Dietary forage components, diets, bunk samples, and orts were assessed for particle size distribution using the 3 -screen $(19,8$, and $1.18 \mathrm{~mm})$ Penn State Particle Separator (Kononoff et al., 2003). Particles were sepa- 
rated into 4 fractions: (1) large $>19 \mathrm{~mm}$; (2) medium, $<19$ and $>8 \mathrm{~mm}$; (3) short, $<8$ and $>1.8 \mathrm{~mm}$; and (4) fine, $<1.8 \mathrm{~mm}$. Each fraction was dried overnight at $105^{\circ} \mathrm{C}$ in a convection oven before determining the relative percentages of DM within each particle-size group for each sample. Physically effective fiber (pef) also was calculated as the percentage of total DM retained on the top 2 screens (19 and $8 \mathrm{~mm}$ ) of the separator (Lammers et al., 1999). Unlike several other studies (Leonardi and Armentano, 2003; Greter et al., 2008; DeVries and von Keyserlingk, 2009) that calculate sorting as the actual DMI of each fraction expressed as a percentage of the predicted DMI of that fraction, feeding procedures in our research facility are based on a bunk-scoring system that allows for ad libitum intake with only a minimal amount of orts. Averaged across the entire feeding trial, this constituted refusal rates (DM basis) of only 1.9, $1.9,2.3,2.5 \%$ for the control, EGH, WS, and CF diets, respectively, with an overall trial rate of $2.1 \%$. Effectively, this approaches total daily consumption of the experimental diets, and renders calculations of sorting factors based (in part) on predicted and actual DMI (Leonardi and Armentano, 2003) of little value because they closely approach $100 \%$, or complete consumption. In lieu of this commonly accepted methodology, our sorting factors were calculated simply as the concentration of each particle fraction in the feed bunk divided by the concentration in the original TMR. Therefore, values equal to 1.00 indicate no sorting, whereas values $>1.00$ indicate that particles were less desirable and sorted against, and values $<1.00$ indicate preference by heifers.

Diet samples obtained from each bunk-sampling time were evaluated sequentially for fiber components (NDF, ADL) by the batch procedures outlined for an Ankom200 Fiber Analyzer. Concentrations of CP were determined by rapid combustion procedures (AOAC International, 1998; method 990.63, Elementar Americas Inc., Mt. Laurel, NJ). Concentrations of NDICP and ADICP were determined by similar methodology, but were used only to calculate TDN (NRC, 2001), and are not reported. Sodium sulfite was omitted from the NDF solution within these procedures to avoid destruction of lignin, and to prevent excessive removal of $\mathrm{CP}$ from the forage fiber matrix (Van Soest et al., 1991). Both NDICP and ADL are required for calculation of energy density (TDN) by the summative equation (NRC, 2001) using the ADL option to calculate truly digestible fiber. Sorting coefficients for NDF, CP, and TDN were then calculated as described previously for various particle-size classes, where values $<1.00$ indicated preference, and those $>1.00$ indicated discrimination against by heifers.

\section{Body Measurements}

Initial and final heifer BW were based on the mean BW of each heifer determined on 3 consecutive mornings immediately before feed was delivered to each pen. Heifers were weighed using a cattle chute (Real Tuff, Clearbrook, MN) equipped with an electronic scale (Tru-Test Inc., Mineral Wells, TX). During $1 \mathrm{~d}$ of the initial and final 3-d weighing periods, frame measurements were taken for each heifer, and included heart girth, body length, hip height, and hip width (Esser et al., 2009). At the same time, BCS was assessed by 2 trained evaluators on a scale of 1 to 5 , where $1=$ emaciated and $5=$ obese (Wildman et al., 1982). For BCS, increments of 0.5 units were applied to best describe the body condition of each heifer.

\section{Statistics}

All data were analyzed by PROC MIXED procedures of SAS Institute Inc. (2002) using a randomized complete block design with 4 blocks. In all cases, the pen served as the experimental unit (St-Pierre, 2007), thereby permitting 15 total degrees of freedom for the statistical analysis of dietary treatments (control, EGH, WS, and CF). Heifers were initially blocked on the basis of weight; therefore, experimental blocks were considered a fixed, rather than random variable. Orthogonal contrasts were used to test the effects of dietary treatment, and included (1) control versus all diets with dilution (EGH, WS, and CF); (2) nonsortable dilution (EGH) versus sortable dilution (WS and $\mathrm{CF}$ ); and (3) moderately sortable dilution (WS) versus highly sortable dilution (CF). Analysis of bunk samples for particle size distribution and nutritive value following feed distribution was conducted by expanding the experimental design to a split-plot with diets considered whole plots and sampling times $(1300,1700,2100$, 0100 , and $0600 \mathrm{~h}$, plus orts) designated as sub-plots. Effects of sampling time were assessed with orthogonal contrasts that tested for linear, quadratic, and cubic effects of time from feeding. Because sampling times were not evenly spaced, PROC IML of SAS Institute Inc. (2002) was used to adjust polynomial coefficients to maintain orthogonality. Gathering of orts was assigned a sampling time of $0830 \mathrm{~h}$ before adjusting polynomial coefficients for unequal spacing. Statistical analysis of heifer activities within each pen were conducted similarly; however, repeated counts of heifer activities within the same pen constituted a repeated measure, which was addressed in the analysis by including SUBJECT $=$ pen (block $\times$ diet) within the REPEATED statement. 


\section{RESULTS AND DISCUSSION}

\section{Diet Formulation}

The weekly analysis of the 4 experiment diets (Table 1) indicated that isonitrogeneity was maintained reasonably across diets, with concentrations of CP ranging narrowly between 13.6 to $13.9 \%$. Dilution increased concentrations of NDF within the diluted diets (range $=$ 50.4 to $53.3 \%$ ) compared with control $(43.3 \%)$. Among diluted diets, WS had slightly greater NDF (53.3\%) than EGH $(50.9 \%)$ or CF $(50.4 \%)$. Overall, the calculated energy density of the control diet (66.8\% TDN) was excessive for heifers within this $\mathrm{BW}$ range based on NRC (2001) estimates of DMI. Inclusion of low-energy forages reduced the energy density by $11.4 \%$ for diluted diets (overall mean $=59.2 \%$ TDN), which ranged narrowly from 58.9 to $59.7 \%$. In part, this was facilitated by the removal of starch associated with corn silage. The concentration of starch was $14.4 \%$ for the control diet, but averaged only $9.5 \%$ across the diluted EGH, $\mathrm{WS}$, and $\mathrm{CF}$ diets.

\section{Nutrient Intakes}

Inclusion of low-energy forages in the TMR offered to heifers was effective in reducing both the caloric density of the diet, as well as DMI. Restriction of DMI by this management approach is well documented using straw formulated at 0,10 , or $20 \%$ of the diet (Greter et al., 2008 ), and in our previous work with eastern gamagrass haylage incorporated at $0,9,18$, or $27 \%$ of the diet (Coblentz et al., 2012). Daily intakes of DM (Table 2) were greater for control than for diets diluted with low-energy forages (11.06 vs. $10.04 \mathrm{~kg} / \mathrm{d} ; P<0.001)$. Despite this desired overall effect, diluted diets were not equivalent with respect to effects on DMI; heifer DMI was reduced by $0.51,1.58$, and $0.97 \mathrm{~kg} / \mathrm{d}$ for EGH, WS, and $\mathrm{CF}$, respectively, relative to control. Heifers offered EGH, which was hypothesized to be nonsortable, exhibited greater DMI than diets with sortable diluting agents (10.55 vs. $9.79 \mathrm{~kg} / \mathrm{d} ; P<0.001)$; however, DMI of $\mathrm{CF}$ was greater than WS (10.09 vs. $9.48 \mathrm{~kg} / \mathrm{d} ; P=$ 0.002). Relationships between diets for intakes of $\mathrm{OM}$ and CP paralleled closely those described for DM.

Collectively, daily intakes of NDF were greater for diets containing low-energy forages compared with control (5.17 vs. $4.79 \mathrm{~kg} / \mathrm{d} ; P<0.001)$; however, intakes of NDF from EGH were greater than observed for WS and $\mathrm{CF}$ (5.37 vs. $5.07 \mathrm{~kg} / \mathrm{d} ; P=0.002)$, which did not differ $(P=0.676)$. Generally, the technique for limiting DMI by diluting diets with low-energy forages is based on gut-fill, where the daily ad libitum DMI limit by

Table 2. Nutrient intakes for replacement heifers consuming diets with or without diluting agents at Marshfield, Wisconsin

\begin{tabular}{|c|c|c|c|c|c|c|c|c|}
\hline \multirow[b]{2}{*}{ Item } & \multicolumn{4}{|c|}{ Diet $^{1}$} & \multirow[b]{2}{*}{ SEM } & \multicolumn{3}{|c|}{ Contrast $^{2}$} \\
\hline & Control & EGH & WS & $\mathrm{CF}$ & & 1 & 2 & 3 \\
\hline \multicolumn{9}{|l|}{ Nutrient intake } \\
\hline DM, kg/d & 11.06 & 10.55 & 9.48 & 10.09 & 0.103 & $<0.001$ & $<0.001$ & 0.002 \\
\hline OM, kg/d & 10.12 & 9.34 & 8.61 & 8.94 & 0.091 & $<0.001$ & 0.001 & 0.033 \\
\hline $\mathrm{CP}, \mathrm{kg} / \mathrm{d}$ & 1.54 & 1.45 & 1.29 & 1.39 & 0.014 & $<0.001$ & $<0.001$ & 0.001 \\
\hline $\mathrm{NDF}, \mathrm{kg} / \mathrm{d}$ & 4.79 & 5.37 & 5.05 & 5.09 & 0.057 & $<0.001$ & 0.002 & 0.676 \\
\hline Digestible $\mathrm{NDF},{ }^{3} \mathrm{~kg} / \mathrm{d}$ & 2.92 & 3.04 & 2.82 & 2.91 & 0.031 & 0.982 & 0.001 & 0.068 \\
\hline $\mathrm{ADF}, \mathrm{kg} / \mathrm{d}$ & 3.01 & 3.35 & 3.25 & 3.38 & 0.036 & $<0.001$ & 0.527 & 0.032 \\
\hline Starch, kg/d & 1.59 & 1.05 & 0.77 & 1.06 & 0.011 & $<0.001$ & $<0.001$ & $<0.001$ \\
\hline Ether extract, kg/d & 0.28 & 0.28 & 0.24 & 0.25 & 0.003 & $<0.001$ & $<0.001$ & 0.157 \\
\hline Ash, kg/d & 0.94 & 1.21 & 0.87 & 1.16 & 0.013 & $<0.001$ & $<0.001$ & $<0.001$ \\
\hline $\mathrm{P}, \mathrm{g} / \mathrm{d}$ & 31.0 & 29.5 & 26.6 & 27.2 & 0.29 & $<0.001$ & $<0.001$ & 0.136 \\
\hline $\mathrm{Ca}, \mathrm{g} / \mathrm{d}$ & 61.9 & 69.6 & 55.9 & 63.6 & 0.71 & 0.200 & $<0.001$ & $<0.001$ \\
\hline $\mathrm{K}, \mathrm{g} / \mathrm{d}$ & 180.2 & 195.1 & 165.9 & 176.6 & 1.98 & 0.672 & $<0.001$ & 0.004 \\
\hline $\mathrm{Mg}, \mathrm{g} / \mathrm{d}$ & 26.6 & 27.4 & 19.9 & 25.2 & 0.27 & $<0.001$ & $<0.001$ & $<0.001$ \\
\hline \multicolumn{9}{|l|}{ Energy intake } \\
\hline TDN, kg/d & 7.39 & 6.22 & 5.66 & 5.97 & 0.059 & $<0.001$ & $<0.001$ & 0.006 \\
\hline ME, Mcal/d & 28.0 & 22.9 & 21.0 & 22.0 & 0.22 & $<0.001$ & 0.001 & 0.007 \\
\hline $\mathrm{NE}_{\mathrm{G}}, \mathrm{Mcal} / \mathrm{d}$ & 11.3 & 7.8 & 7.3 & 7.6 & 0.08 & $<0.001$ & 0.003 & 0.032 \\
\hline $\mathrm{NE}_{\mathrm{M}}, \mathrm{Mcal} / \mathrm{d}$ & 18.0 & 13.8 & 12.7 & 13.3 & 0.13 & $<0.001$ & 0.001 & 0.009 \\
\hline
\end{tabular}

${ }^{1}$ Control = alfalfa haylage/corn silage diet containing no diluting agent and offered for ad libitum intake; EGH = alfalfa haylage/corn silage diet

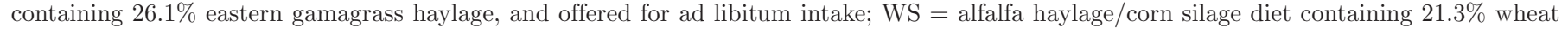

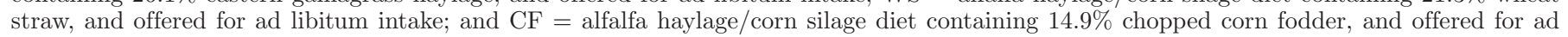
libitum intake.

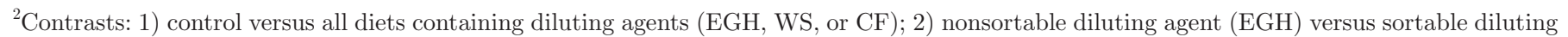
agents (WS or CF); and 3) WS versus CF.

${ }^{3}$ Values based on NDF intakes and a 48-h in vitro determination of NDF digestibility.

${ }^{4}$ Energy calculations based on NRC (2001). 
heifers is constrained at approximately $1.0 \%$ of $\mathrm{BW}$ consumed as NDF (Hoffman et al., 2008). This theorized constraint proved very accurate for the 3 diets diluted with low-energy forages; based on the mean trial BW, intakes of NDF were calculated to be 1.02, 0.97, and $0.96 \%$ of BW for EGH, WS, and CF, respectively, but were slightly lower for control (0.89\% of BW).

Intakes of digestible NDF based on a 48-h in vitro NDFD did not differ between the control and diluted diets (overall mean $=2.92 \mathrm{~kg} / \mathrm{d} ; P=0.982$ ), but intake of digestible NDF from EGH was greater than from WS and CF (3.04 vs. $2.87 \mathrm{~kg} / \mathrm{d} ; P=0.001)$; however, this difference was largely driven by DMI because concentrations of both NDF and 48-h NDFD varied minimally across diets diluted with low-energy forages. Daily intakes of $\mathrm{ADF}$ were greater from diets diluted with low-energy forages than for control (3.33 vs. $3.01 \mathrm{~kg} / \mathrm{d}$; $P<0.001)$. Unlike NDF, intakes of ADF did not differ between EGH and sortable diluted diets (mean $=3.33$ $\mathrm{kg} / \mathrm{d} ; P=0.527)$. Among the remaining nutritional components, the response for starch is noteworthy; substituting low-energy forages for corn silage reduced the daily intake of starch ( 1.59 vs. $0.96 \mathrm{~kg} / \mathrm{d} ; P<0.001)$. Other differences observed for intakes of starch were largely explained by the reduced DMI observed for WS relative to EGH and $\mathrm{CF}$; although not tested statistically, starch intakes for the latter 2 diets were almost identical $($ mean $=1.06 \mathrm{~kg} / \mathrm{d})$. Low-energy forages were effective $(P<0.001)$ in reducing the daily intake of energy expressed as TDN, or partitioned into $\mathrm{ME}, \mathrm{NE}_{\mathrm{G}}$, and $\mathrm{NE}_{\mathrm{M}}$. For TDN, this represented a $19.5 \%$ reduction for diluted diets relative to control (7.39 vs. $5.95 \mathrm{~kg} / \mathrm{d}$; $P<0.001)$. Significant contrasts among diluted diets also were detected for TDN $(P \leq 0.006)$, but these were driven strongly by the differences in total DMI among these diets discussed previously.

\section{Fecal Output and Nutrient Digestibilities}

Fecal output (Table 3) for EGH was greater than observed for sortable diluted diets (4.12 vs. $3.53 \mathrm{~kg} / \mathrm{d}$; $P<0.001$ ), but daily fecal outputs for WS and $\mathrm{CF}$ did not differ $(P=0.242)$. Fecal output for control $(3.76$ $\mathrm{kg} / \mathrm{d}$ ) was numerically intermediate between EGH and sortable diluted diets, and did not differ $(P=0.613)$ from the collective response observed for all diluted diets. Digestibilities of DM and OM were greater for control than for all diluted diets $(P<0.001)$; however, in each case, digestibility for EGH was less $(P \leq 0.001)$ than observed for sortable diluted diets, and digestibility for $\mathrm{CF}$ was greater than observed for WS $(P \leq$ 0.037). For digestibilities of fiber components, the most noteworthy response was observed for comparisons of EGH with sortable diluted diets, in which digestibili- ties of NDF, ADF, and hemicellulose were greater $(P$ $\leq 0.043)$ for WS and CF compared with EGH. The opposite response was observed for apparent $\mathrm{N}$ digestibility, where EGH exhibited greater digestibility than the sortable diluted diets (64.1 vs. $61.6 \% ; P=0.003$ ). Generally, digestibilities of forage components were relatively extensive, with the most pronounced difference among diets being the greater digestibilities of DM and $\mathrm{OM}$ for control compared with diluted diets, which probably reflects the greater concentration of starch and other nonfiber components within the control diet.

\section{Heifer Growth and Performance}

Initial body measurements generally were similar across treatment groups, exhibiting no significant comparative contrasts for BW, body length, hip height, or BCS $(P \geq 0.061$; Table 4). For heart girth, a difference was present between heifers assigned to control compared with those assigned to diets diluted with low-energy forages (192 vs. $190 \mathrm{~cm} ; P=0.039$ ), but this difference was small and of questionable practical relevance.

Final BW for heifers offered control was greater than for heifers offered all other diets (610 vs. 580 $\mathrm{kg} ; P<0.001)$. Among diluted diets, the final BW for heifers offered EGH $(584 \mathrm{~kg})$ did not differ from the collective response of sortable diluted diets $(P=$ 0.279 ), but a $24-\mathrm{kg}$ difference was present in final BW between WS and CF (566 vs. $590 \mathrm{~kg} ; P=0.005$ ). No differences among diets were detected for final body length $(P \geq 0.186)$ or hip height $(P \geq 0.487)$. Final heart girth was greater for control than for diluted diets (204 vs. $198 \mathrm{~cm} ; P=0.001$ ). Similarly, final BCS for heifers offered the control diet was greater than observed for diets diluted with low-energy forages (3.7 vs. 3.5; $P=0.001)$; however, heifers offered EGH also exhibited a greater final BCS than WS and CF (3.6 vs. $3.4 ; P=0.006)$.

Total weight gain (140 vs. $109 \mathrm{~kg} ; P<0.001)$, ADG (1.16 vs. $0.91 \mathrm{~kg} / \mathrm{d} ; P<0.001)$, change in heart girth $(12$ vs. $8 \mathrm{~cm} ; P=0.002)$, and change in BCS (0.5 vs. 0.3 units; $P=0.006)$ all were greater, and the feed:gain ratio was less (9.6 vs. $11.1 \mathrm{~kg} / \mathrm{kg} ; P=0.002$ ), for heifers offered the control diet compared with diets diluted with low-quality forages. Within the diluted diets, total weight gain, ADG, and the change in BCS were greater $(P \leq 0.027)$ for heifers offered the EGH diet compared with those that included sortable diluting agents; however, responses to the $\mathrm{CF}$ and WS diets differed $(P$ $\leq 0.018$ ) with increases in weight and body condition greater for $\mathrm{CF}$ in each case. Although not compared directly, heifer performance from EGH and CF diets was almost identical across all measures of growth. 
Table 3. Daily DMI, fecal output, and digestibilities of various forage fractions by replacement heifers consuming diets with or without diluting agents at Marshfield, Wisconsin ${ }^{1}$

\begin{tabular}{|c|c|c|c|c|c|c|c|c|}
\hline \multirow[b]{2}{*}{ Item } & \multicolumn{4}{|c|}{$\operatorname{Diet}^{2}$} & \multirow[b]{2}{*}{ SEM } & \multicolumn{3}{|c|}{ Contrast $^{3}$} \\
\hline & Control & EGH & WS & $\mathrm{CF}$ & & 1 & 2 & 3 \\
\hline$\overline{\mathrm{DMI},{ }^{4} \mathrm{~kg} / \mathrm{d}}$ & 11.46 & 10.72 & 9.35 & 9.87 & 0.152 & $<0.001$ & $<0.001$ & 0.038 \\
\hline Fecal DM output, ${ }^{4} \mathrm{~kg} / \mathrm{d}$ & 3.76 & 4.12 & 3.48 & 3.58 & 0.056 & 0.613 & $<0.001$ & 0.242 \\
\hline \multicolumn{9}{|l|}{ Digestibility } \\
\hline DM, \% & 67.1 & 61.6 & 62.7 & 63.7 & 0.26 & $<0.001$ & 0.001 & 0.037 \\
\hline OM, \% & 68.8 & 62.7 & 64.9 & 66.6 & 0.24 & $<0.001$ & $<0.001$ & 0.001 \\
\hline Hemicellulose, \% & 59.5 & 59.5 & 60.9 & 60.9 & 0.49 & 0.133 & 0.043 & 0.980 \\
\hline Apparent N, \% & 63.6 & 64.1 & 62.0 & 61.1 & 0.51 & 0.074 & 0.003 & 0.231 \\
\hline
\end{tabular}

${ }^{1}$ Digestibilities are based on residual NDF following a 240-h ruminal incubation in situ as an internal marker to determine fecal output.

${ }^{2}$ Control $=$ alfalfa haylage/corn silage diet containing no diluting agent and offered for ad libitum intake; EGH = alfalfa haylage/corn silage diet containing $26.1 \%$ eastern gamagrass haylage, and offered for ad libitum intake; WS = alfalfa haylage/corn silage diet containing $21.3 \%$ wheat straw, and offered for ad libitum intake; and $\mathrm{CF}=$ alfalfa haylage/corn silage diet containing $14.9 \%$ chopped corn fodder, and offered for ad libitum intake.

${ }^{3}$ Contrasts: (1) control versus all diets containing diluting agents (EGH, WS, or CF); (2) nonsortable diluting agent (EGH) versus sortable diluting agents (WS or CF); and (3) WS versus CF.

${ }^{4}$ Based on wk 10, 15, and 17 of the trial only. All calculations were based on collective DMI and orts for the entire week of analysis, and then reported on a daily per heifer basis.

As expected, the ADG for heifers offered control was excessive $(1.16 \mathrm{~kg} / \mathrm{d})$ for normal targets for Holstein heifers of this weight range $(0.76$ to $0.84 \mathrm{~kg} / \mathrm{d}$; Hoffman, 1997), and this was corroborated visually in the final BCS (3.7) that suggests overconditioning. The addition of diluting agents reduced caloric density and DMI of all diluted diets; however, heifer ADG from EGH $(0.98 \mathrm{~kg} / \mathrm{d})$ and $\mathrm{CF}(0.97 \mathrm{~kg} / \mathrm{d})$ both exceeded

Table 4. Effects of diet on body size and growth performance of 128 Holstein replacement heifers at Marshfield, Wisconsin

\begin{tabular}{|c|c|c|c|c|c|c|c|c|}
\hline \multirow[b]{2}{*}{ Item } & \multicolumn{4}{|c|}{$\operatorname{Diet}^{1}$} & \multirow[b]{2}{*}{ SEM } & \multicolumn{3}{|c|}{ Contrast $^{2}$} \\
\hline & Control & EGH & WS & $\mathrm{CF}$ & & 1 & 2 & 3 \\
\hline \multicolumn{9}{|l|}{ Initial } \\
\hline $\mathrm{BW}, \mathrm{kg}$ & 470 & 467 & 471 & 473 & 3.7 & 0.945 & 0.279 & 0.731 \\
\hline Length, cm & 151 & 153 & 153 & 153 & 0.8 & 0.061 & 0.945 & 0.711 \\
\hline Hip height, cm & 139 & 138 & 139 & 139 & 0.8 & 0.663 & 0.333 & 0.657 \\
\hline Heart girth, $\mathrm{cm}$ & 192 & 190 & 190 & 190 & 0.8 & 0.039 & 0.984 & 0.801 \\
\hline $\mathrm{BW}, \mathrm{kg}$ & 610 & 584 & 566 & 590 & 4.6 & $<0.001$ & 0.279 & 0.005 \\
\hline Length, cm & 161 & 163 & 161 & 161 & 1.4 & 0.734 & 0.186 & 0.690 \\
\hline Hip height, cm & 144 & 143 & 143 & 144 & 0.9 & 0.492 & 0.830 & 0.487 \\
\hline Heart girth, cm & 204 & 198 & 197 & 198 & 1.1 & 0.001 & 0.786 & 0.330 \\
\hline $\mathrm{BCS}$ & 3.7 & 3.6 & 3.3 & 3.5 & 0.04 & 0.001 & 0.006 & 0.051 \\
\hline \multicolumn{9}{|l|}{ Growth } \\
\hline Weight gain, kg & 140 & 117 & 95 & 116 & 3.6 & $<0.001$ & 0.022 & 0.002 \\
\hline BCS & 0.5 & 0.4 & 0.2 & 0.4 & 0.04 & 0.006 & 0.027 & 0.018 \\
\hline Feed:gain, $\mathrm{kg} / \mathrm{kg}$ & 9.6 & 10.8 & 12.1 & 10.5 & 0.32 & 0.002 & 0.263 & 0.007 \\
\hline
\end{tabular}

${ }^{1}$ Control $=$ alfalfa haylage/corn silage diet containing no diluting agent and offered for ad libitum intake; EGH = alfalfa haylage/corn silage diet containing $26.1 \%$ eastern gamagrass haylage, and offered for ad libitum intake; WS = alfalfa haylage/corn silage diet containing $21.3 \%$ wheat straw, and offered for ad libitum intake; and CF = alfalfa haylage/corn silage diet containing $14.9 \%$ chopped corn fodder, and offered for ad libitum intake.

${ }^{2}$ Contrasts: 1) control versus all diets containing diluting agents (EGH, WS, or CF); 2) nonsortable diluting agent (EGH) versus sortable diluting agents (WS or CF); and 3) WS versus CF.

${ }^{3}$ ANOVA using the coefficient of variation for total gain (or ADG) obtained from each research pen as the response variable. 
expectations based on the energy density (58.9 and $59.1 \%$ TDN, respectively) of these diets (NRC, 2001). Based on the model of Hoffman et al. (2008) for predicting DMI of Holstein heifers, these elevated weight gains cannot entirely be explained on the basis of DMI; actual DMI for EGH exceeded predicted by $0.27 \mathrm{~kg} / \mathrm{d}$ (10.55 vs. $10.28 \mathrm{~kg} / \mathrm{d}$ ), but actual DMI for CF was less than predicted (10.09 vs. $10.39 \mathrm{~kg} / \mathrm{d})$. For WS, heifers consumed $0.52 \mathrm{~kg} / \mathrm{d}$ less than projected (9.48 vs. 10.00 $\mathrm{kg} / \mathrm{d})$; however, their ADG $(0.79 \mathrm{~kg} / \mathrm{d})$ was within the recommended range for Holstein heifers calving at 24 mo of age (Hoffman, 1997). For growing dairy heifers, Quigley et al. (1986) and Tomlinson et al. (1991) reported negative correlations between DMI and NDF concentrations in the diet whenever NDF exceeded $42 \%$ $(\mathrm{r}=-0.42)$ and $41 \%(\mathrm{r}=-0.28)$ of DM, respectively. Quigley et al. (1986) also reported a positive correlation between DMI and bulk density $(\mathrm{r}=0.39)$ whenever the NDF concentration exceeded $42 \%$, but no correlations between DMI and NDF or bulk density were observed whenever NDF was less than $42 \%$. The work of Quigley et al. (1986) suggests competing effects of NDF and bulk density on DMI by dairy heifers; although bulk density was not measured in the present study, particle size distribution for eastern gamagrass haylage (Table 5 ) showed that only $4.7 \%$ of DM was comprised of large particles. This suggests a greater bulk density for the EGH diet compared with other diluted diets, which may explain some of the differences in DMI across diluted diets, and particularly between EGH and WS.

Previous work has suggested that limited bunk space does not necessarily affect the mean group growth rate, but will affect growth rates of individual heifers within the group (Longenbach et al., 1999). As such, several studies (Longenbach et al., 1999; Greter et al., 2010; Kitts et al., 2011) have used measures of variation within pen replicates as response variables to assess undesirable variability in growth performance among heifers within a common pen. An ANOVA conducted using the CV for weight gain within each pen as a response variable exhibited no significant $(P \geq 0.212)$ contrasts; however, a numerical trend was observed in which the CV increased based on the expected sorting characteristics of the diet from a minimum of $10.4 \%$ for control to a maximum of $15.5 \%$ for CF. It should be noted that our restriction of bunk space (6 headlocking gates $/ 8$ heifers) did not include concomitant limitations in pen space, or free-stall availability, which might occur in many commercial feeding operations.

\section{Sorting Characteristics of Diets}

Among the 5 forages comprising the experimental diets, eastern gamagrass haylage exhibited the smallest percentage of DM partitioned into large $(4.7 \pm$ $3.68 \%$ ) and combined large and medium (pef; $49.0 \pm$ $5.68 \%$ ) particles (Table 5). Conversely, eastern gamagrass haylage also consisted of the largest percentage of DM partitioned in short $(33.5 \pm 2.34 \%)$ and fine $(17.5 \pm 3.65 \%)$ particles. Among the remaining forages, the starkest contrast to eastern gamagrass haylage occurred for chopped corn fodder, which consisted of 78.5 $\pm 6.28,13.2 \pm 2.69$, and $8.3 \pm 3.67 \%$ pef, short, and fine particles, respectively. Corn silage, alfalfa haylage, and chopped wheat straw exhibited particle-size distribution characteristics that were intermediate between the described extremes for eastern gamagrass haylage and chopped corn fodder. Because the diluted diets ranged very narrowly with respect to NDF, differences in DMI relative to control (described previously) may be partially explained by physical or other factors, such as particle length. Jaster and Murphy (1983) reported increased voluntary intakes of DM, NDF, ADF, hemicellulose, and cellulose after long-stem alfalfa hay was chopped and offered to 340-kg dairy heifers; similarly, Hoffman et al. (2006) reported greater DMI when alfalfa hay was processed through the TMR compared with long-stem or bale-cut forms top-dressed on the TMR.

The distribution of forage DM on the basis of particle size, as well as sorting factors associated with the experimental diets, are found in Table 6 . The concentra-

Table 5. Particle size distribution $( \pm \mathrm{SD})$ for individual dietary component forages subsequently blended into TMR diets offered to Holstein dairy heifers at Marshfield, Wisconsin ${ }^{1}$

\begin{tabular}{|c|c|c|c|c|c|}
\hline Item, $\%$ of DM & Large & Medium & Short & Fine & pef \\
\hline \multicolumn{6}{|l|}{ Component forage } \\
\hline Corn silage & $9.3 \pm 5.75$ & $56.9 \pm 7.87$ & $22.8 \pm 7.27$ & $11.0 \pm 6.21$ & $66.2 \pm 11.64$ \\
\hline Wheat straw & $32.1 \pm 10.18$ & $39.0 \pm 4.77$ & $16.7 \pm 3.72$ & $12.2 \pm 7.03$ & $71.1 \pm 10.73$ \\
\hline Corn fodder & $43.4 \pm 8.27$ & $35.1 \pm 4.39$ & $13.2 \pm 2.69$ & $8.3 \pm 3.67$ & $78.5 \pm 6.28$ \\
\hline
\end{tabular}

${ }^{1}$ Particle size designations determined with the Penn State Particle Separator, which has 19-, 8-, and 1.18-mm screens, plus a bottom pan that retain large, medium, short, and fine particles, respectively. The physically effective fiber (pef) was defined as the percentage of DM retained on the 19- and 8-mm screens. 
Table 6. Interactions of diet and observation time for particle size distribution and sorting by 128 Holstein dairy heifers

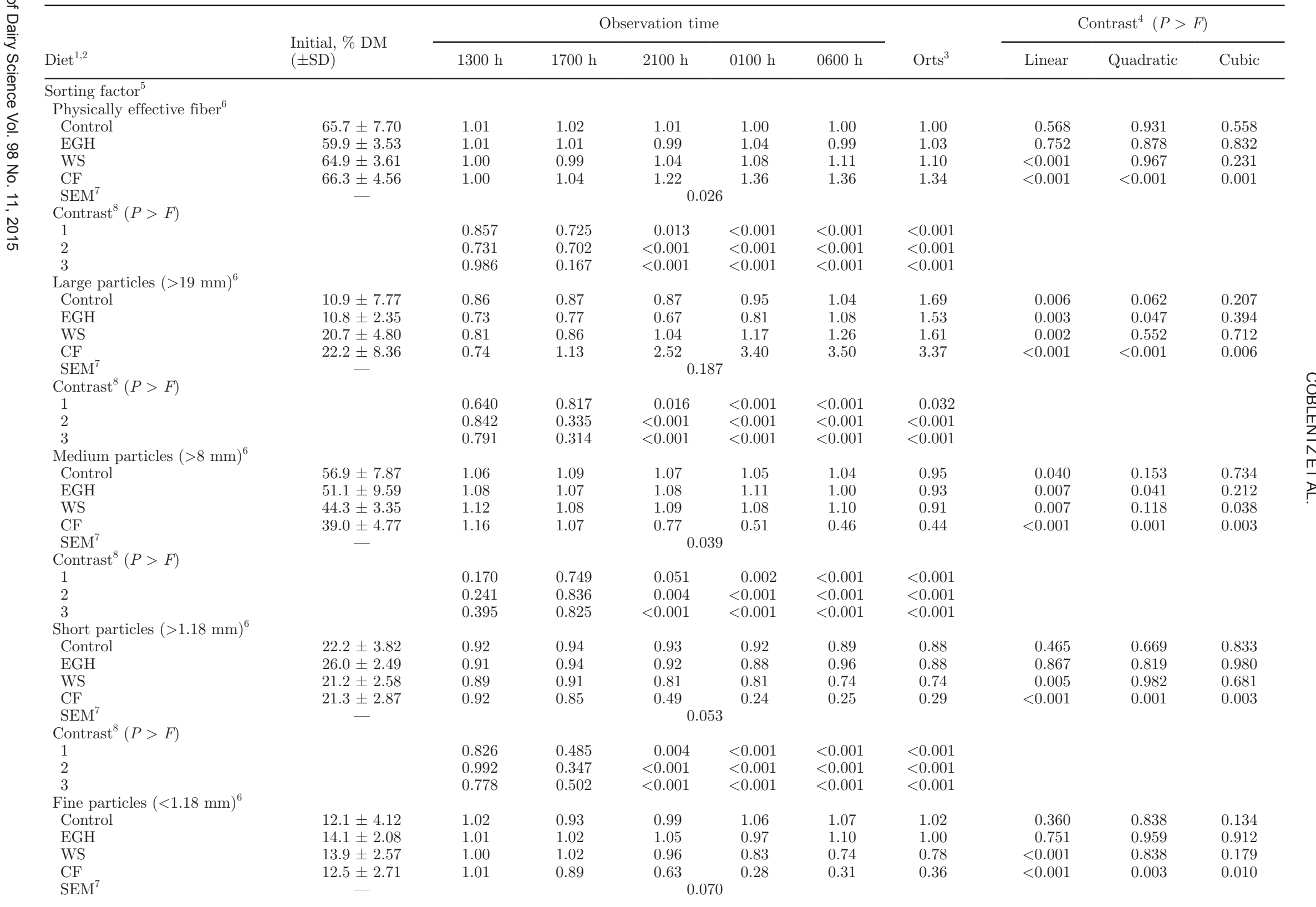


tion of pef, short, and fine particles within all blended experimental diets were relatively similar, ranging from 59.9 to $66.3 \%, 21.2$ to $26.0 \%$, and 12.1 to $14.1 \%$, respectively. Generally, our original hypothesis that eastern gamagrass haylage was largely nonsortable when included in dairy-heifer diets proved to be correct. Physically effective fiber retained on the top 2 screens of the particle separator was static across sampling times for both control (overall mean $=1.01 ; P \geq 0.558$ ) and EGH (overall mean $=1.01 ; P \geq 0.752$ ). The concentration of pef from WS increased linearly $(P<0.001)$ across sampling times, exhibiting a maximum sorting factor of 1.11, but higher-order polynomial responses were not detected $(P \geq 0.231)$. Sorting factors from $\mathrm{CF}$ reached maxima of 1.36 at both 0100 and $0600 \mathrm{~h}$, indicating aggressive sorting against pef particles, especially between 1700 and $0100 \mathrm{~h}$. These overall responses were explained by linear, quadratic, and cubic effects $(P \leq 0.001)$ of sampling time. Although the sorting of pef particles within the control and EGH diets was static, this response masked competing responses for individual large and medium particles comprising pef, which were treated with discrimination and preference, respectively, by heifers. However, these contrasting responses for large and medium particles were far more distinct for WS and CF diets. For CF, sorting factors for large particles increased with multiple polynomial effects $(P \leq 0.006)$ to a maximum of 3.50 , and decreased with multiple effects $(P \leq 0.003)$ for medium particles to a preferential sorting factor of 0.44. Overall, the static sorting responses for pef observed for the control and EGH diets, as well as the discriminatory responses against pef for the WS and CF diets, masked competing, but very distinct, sorting responses for large and medium particles, which were exacerbated for WS, and even more so for the $\mathrm{CF}$ diet. It also is important to note that although inclusion of low-energy forages was effective in reducing DMI and weight gains by heifers compared with control, these responses could not be linked directly to sorting behaviors by heifers. Heifers sorted large particles within CF more aggressively than observed for WS; however, as discussed previously, DMI $(10.09$ vs. $9.48 \mathrm{~kg} / \mathrm{d} ; P=0.002)$ and weight gains $(116$ vs. $95 \mathrm{~kg} ; P=0.002$ ) were greater for $\mathrm{CF}$ than for WS.

Sorting factors for short particles measured from control $($ mean $=0.91)$ and EGH $($ mean $=0.92)$ did not change $(P \geq 0.465)$ across sampling times, and similar responses $(P \geq 0.134)$ were observed for fine particles. Heifers offered WS exhibited moderate sorting in favor of short and fine particles; sorting factors for these particle sizes declined linearly $(P \leq 0.005)$ across bunksampling times, reaching minima of 0.74 in both cases, but other polynomial effects were not detected $(P \geq$ $0.179)$. Sorting in favor of short and fine particles by 
Table 7. Interactions of diet and observation time for forage quality parameters within the feedbunk for 128 Holstein dairy heifers fed once daily between 0900 and $1100 \mathrm{~h}$ at Marshfield, Wisconsin

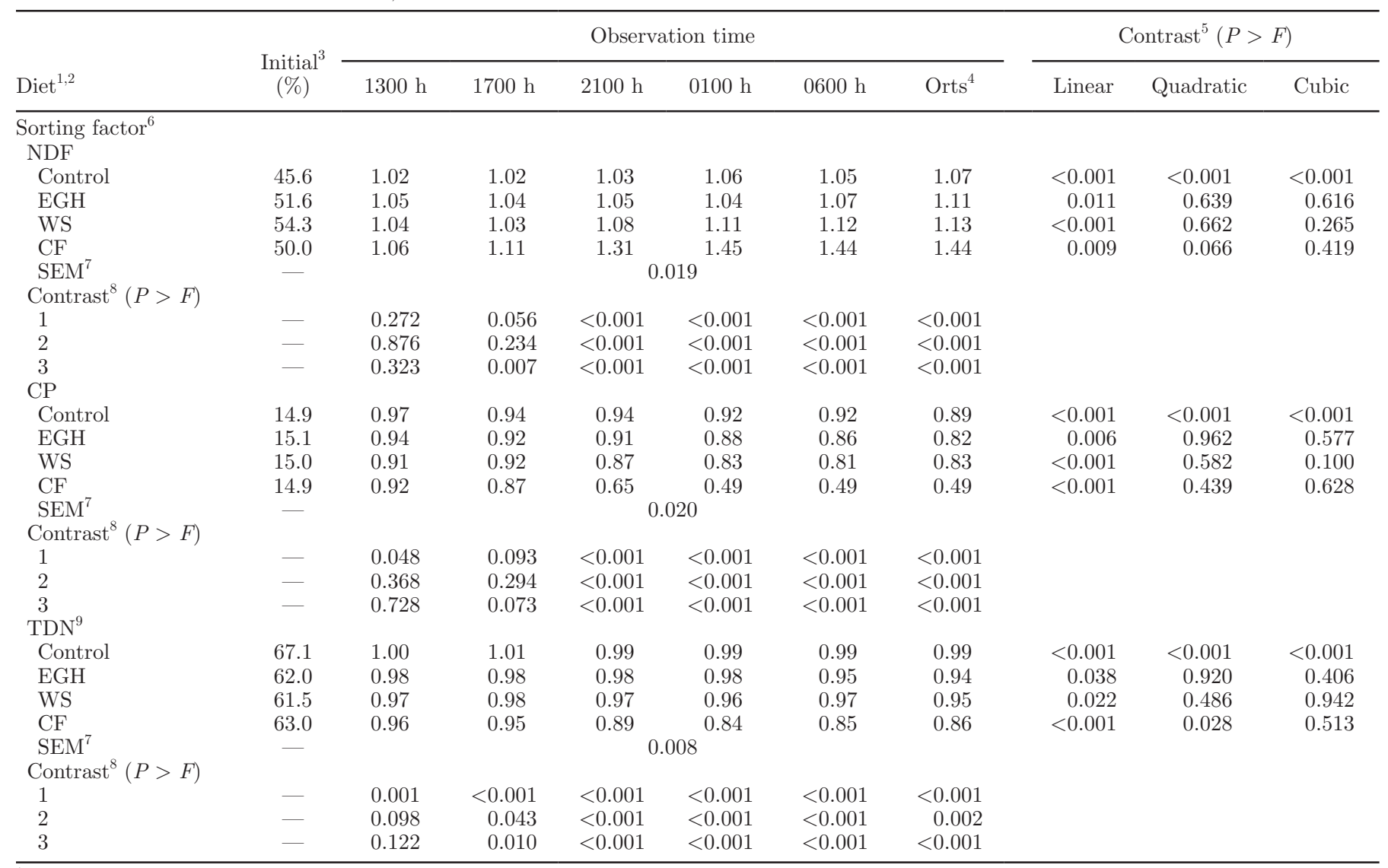

${ }^{1}$ Control $=$ alfalfa haylage/corn silage diet containing no diluting agent and offered for ad libitum intake; EGH = alfalfa haylage/corn silage diet containing $26.1 \%$ eastern gamagrass haylage, and offered for ad libitum intake; WS = alfalfa haylage/corn silage diet containing $21.3 \%$ wheat straw, and offered for ad libitum intake; and $\mathrm{CF}=$ alfalfa haylage/corn silage diet containing $14.9 \%$ chopped corn fodder, and offered for ad libitum intake.

${ }^{2}$ Feedbunks were sampled during wk $6,8,12$, and 16 of the trial. Mean DMI for the diets during those weeks were control, $89.8 \mathrm{~kg} /$ pen per $\mathrm{d}$; EGH, $87.2 \mathrm{~kg} /$ pen per d; WS, $78.1 \mathrm{~kg} /$ pen per d; and CF, $81.9 \mathrm{~kg} /$ pen per d. Similarly, mean orts collected during those weeks were control, $2.1 \mathrm{~kg} /$ pen per d; EGH, $2.1 \mathrm{~kg} /$ pen per d; WS, $2.4 \mathrm{~kg} /$ pen per d; and CF, $1.9 \mathrm{~kg} /$ pen per d. The SEM for mean DMI and orts were 2.52 and $0.14 \mathrm{~kg} /$ pen per d, respectively.

${ }^{3}$ Mean initial concentration of NDF, CP, or TDN as determined from samples of treatment diets composited daily within week, and then over experimental periods.

${ }^{4}$ Orts gathered at approximately $0830 \mathrm{~h}$ each morning.

${ }^{5}$ Orthogonal contrasts evaluating linear, quadratic, and cubic effects of sampling time.

${ }^{6}$ Sorting factor: concentration of NDF, CP, or TDN in the feed bunk at each sampling time divided by the concentration of that nutritional component in the original TMR.

${ }^{7} \mathrm{SEM}$, standard error of all interactive means.

${ }^{8}$ Contrasts: (1) control versus all diets containing diluting agents (EGH, WS, or CF); (2) nonsortable diluting agent (EGH) versus sortable diluting agents (WS or CF); and (3) WS versus CF.

${ }^{9}$ Calculated per NRC (2001) equations.

heifers offered $\mathrm{CF}$ was much more aggressive than for WS as sorting factors reached minima of 0.24 and 0.28 , respectively, and differed $(P \leq 0.002)$ from WS at all bunk-sampling times at $2100 \mathrm{~h}$ or later. Sorting factors for $\mathrm{CF}$ also changed with linear, quadratic, and cubic polynomial effects $(P \leq 0.010)$ of sampling time for both short and fine particles, most of which were driven by rapid declines between 1700 and $0100 \mathrm{~h}$.
Generally, sorting responses exhibited by heifers during this trial were similar to those described for other studies. Greter et al. (2008) observed increased preference for fine, short, and medium particles as straw was added to the diet at 10 and $20 \%$ inclusion rates; however, prepubescent heifers discriminated against large particles, regardless of diet dilution rate. In that study, inclusion of straw at 10 and $20 \%$ of the diet 
also resulted in a linear reduction of DMI. Hoffman et al. (2006) observed increased sorting of large particles and reduced DMI when gravid heifers were offered diets with top-dressed, long-stem, or bale-cut hay compared with diets where hay was shredded within the TMR mixer. Lactating cows also are known to sort against large particles (Leonardi and Armentano, 2003); these behaviors are known to be exacerbated when low-forage (50.7\%) are offered compared with high-forage (62.3\%) diets (DeVries et al., 2007), and within free-stall compared with tie-stall feeding situations (Leonardi and Armentano, 2007). However, this response to particle size is not consistent. Recently, Greter et al. (2013) reported that limit-fed heifers consuming a nutrientdense ration show a preference for long-particle compared with short-particle oat straw, perhaps because longer particles are more satisfactory for meeting rumen fill or behavioral foraging needs under a limit-feeding management program.

\section{Sorting Effects on Diet Quality}

Sorting factors calculated for concentrations of NDF within the feed bunk increased for all diets over sam- pling times (Table 7$)$, exhibiting linear $(P \leq 0.009)$ effects in each case. Higher-ordered effects $(P<0.001)$ also were observed for control, but not for the other diets $(P \geq 0.066)$. Although heifers discriminated against NDF for all diets, the magnitude of these responses were relatively modest for control, EGH, and WS, but far greater for $\mathrm{CF}$, which reached a maximum sorting factor of 1.45 , or a $45 \%$ increase in the concentration of NDF by $0100 \mathrm{~h}$. Furthermore, this aggressive discrimination against NDF was detected as early as $1700 \mathrm{~h}$, at which time sorting factors for CF and WS differed (1.11 vs. $1.03 ; P=0.007$ ). Generally, relative to NDF, inverse sorting responses were observed for $\mathrm{CP}$ and TDN, where sorting factors $<1.00$ indicated preferential selection by heifers. As observed for NDF, the change in sorting factors across sampling times was more distinct for $\mathrm{CF}$ compared with the other diets.

Feeding management within our research barn is designed to allow for ad libitum DMI, but with a very tight tolerance for minimizing orts. This management approach is consistent with extension recommendations for managing straw within TMR diets for heifers (Shaver and Hoffman, 2010), and these results suggest such efforts to minimize orts ensure (near) total

Table 8. Interactions of diet and observation time for eating and resting behaviors of 128 Holstein dairy heifers fed once daily between 0900 and $1100 \mathrm{~h}$ at Marshfield, Wisconsin (\% of heifers)

\begin{tabular}{|c|c|c|c|c|c|}
\hline \multirow[b]{2}{*}{$\operatorname{Diet}^{1}$} & \multicolumn{5}{|c|}{ Observation time } \\
\hline & $1300 \mathrm{~h}$ & $1700 \mathrm{~h}$ & $2100 \mathrm{~h}$ & $0100 \mathrm{~h}$ & $0600 \mathrm{~h}$ \\
\hline \multicolumn{6}{|l|}{ Eating } \\
\hline Control & 21.6 & 18.0 & 22.0 & 3.9 & 3.3 \\
\hline EGH & 40.6 & 25.6 & 26.6 & 7.7 & 5.9 \\
\hline WS & 43.9 & 27.3 & 25.2 & 4.1 & 6.4 \\
\hline $\mathrm{CF}$ & 34.7 & 31.9 & 18.9 & 3.1 & 2.8 \\
\hline $\mathrm{SEM}^{2}$ & & & 2.10 & & \\
\hline \multicolumn{6}{|l|}{ Contrast ${ }^{3}$} \\
\hline 1 & $<0.001$ & $<0.001$ & 0.538 & 0.671 & 0.471 \\
\hline 2 & 0.609 & 0.131 & 0.087 & 0.124 & 0.609 \\
\hline 3 & 0.004 & 0.137 & 0.043 & 0.755 & 0.235 \\
\hline \multicolumn{6}{|l|}{ Lying } \\
\hline Control & 55.8 & 62.2 & 46.7 & 86.4 & 89.4 \\
\hline EGH & 35.2 & 57.2 & 42.8 & 79.4 & 86.9 \\
\hline WS & 40.3 & 59.7 & 52.7 & 88.3 & 87.5 \\
\hline $\mathrm{CF}$ & 43.8 & 50.0 & 55.9 & 85.5 & 89.7 \\
\hline SEM & & & 2.82 & & \\
\hline \multicolumn{6}{|l|}{ Contrast $^{3}$} \\
\hline 1 & $<0.001$ & 0.051 & 0.257 & 0.536 & 0.680 \\
\hline 2 & 0.054 & 0.501 & 0.002 & 0.036 & 0.622 \\
\hline 3 & 0.394 & 0.020 & 0.416 & 0.485 & 0.586 \\
\hline
\end{tabular}

${ }^{1}$ Control = alfalfa haylage/corn silage diet containing no diluting agent and offered for ad libitum intake; EGH $=$ alfalfa haylage/corn silage diet containing $26.1 \%$ eastern gamagrass haylage, and offered for ad libitum intake; WS = alfalfa haylage/corn silage diet containing $21.3 \%$ wheat straw, and offered for ad libitum intake; and $\mathrm{CF}=$ alfalfa haylage/corn silage diet containing $14.9 \%$ chopped corn fodder, and offered for ad libitum intake.

${ }^{2} \mathrm{SEM}$, standard error of all interactive means.

${ }^{3}$ Contrasts: (1) control versus all diets containing diluting agents (EGH, WS, or CF); (2) nonsortable diluting agent (EGH) versus sortable diluting agents (WS or CF); and (3) WS versus CF. 
Table 9. Main effects of various other heifer behaviors for Holstein dairy heifers fed once daily between 0900 and $1100 \mathrm{~h}$ at Marshfield, Wisconsin (\% of heifers)

\begin{tabular}{|c|c|c|c|c|}
\hline \multirow[b]{2}{*}{ Treatment } & \multicolumn{4}{|c|}{ Behavior $^{1}$} \\
\hline & Refused & Perching & Inactive standing & Other \\
\hline \multicolumn{5}{|l|}{$\overline{\text { Diet }^{2}}$} \\
\hline Control & 0.3 & 7.2 & 9.5 & 2.5 \\
\hline EGH & 0.7 & 4.6 & 11.8 & 3.2 \\
\hline WS & 0.7 & 5.2 & 6.5 & 2.9 \\
\hline $\mathrm{CF}$ & 0.8 & 6.6 & 8.5 & 2.5 \\
\hline SEM & 0.21 & 0.53 & 0.67 & 0.50 \\
\hline \multicolumn{5}{|c|}{ Observation time } \\
\hline $1300 \mathrm{~h}$ & 0.9 & 5.6 & 11.6 & 2.9 \\
\hline $1700 \mathrm{~h}$ & 0.2 & 6.0 & 8.7 & 2.1 \\
\hline $2100 \mathrm{~h}$ & 2.0 & 8.8 & 17.3 & 8.1 \\
\hline $0100 \mathrm{~h}$ & 0 & 5.2 & 4.5 & 0.7 \\
\hline $0600 \mathrm{~h}$ & 0 & 3.8 & 3.2 & 0 \\
\hline SEM & 0.23 & 0.52 & 0.75 & 0.56 \\
\hline \multicolumn{5}{|l|}{ Contrast $^{3}$} \\
\hline 1 & 0.160 & 0.021 & 0.517 & 0.510 \\
\hline 2 & 0.904 & 0.086 & 0.001 & 0.449 \\
\hline 3 & 0.678 & 0.099 & 0.067 & 0.579 \\
\hline 4 & 0.006 & 0.005 & $<0.001$ & $<0.001$ \\
\hline 5 & 0.025 & $<0.001$ & $<0.001$ & $<0.001$ \\
\hline 6 & 0.877 & 0.614 & 0.230 & 0.297 \\
\hline
\end{tabular}

${ }^{1}$ Behaviors: refused, heifers actively blocked from eating by other dominant heifers; perching, heifers standing with at least 2 feet in a freestall; inactive standing, heifers standing in alleys without demonstrating any activity; other, heifers engaged in other activities, mostly commonly drinking or estrus.

${ }^{2} \mathrm{Control}=$ alfalfa haylage/corn silage diet containing no diluting agent and offered for ad libitum intake; EGH $=$ alfalfa haylage/corn silage diet containing $26.1 \%$ eastern gamagrass haylage, and offered for ad libitum intake; WS = alfalfa haylage/corn silage diet containing $21.3 \%$ wheat straw, and offered for ad libitum intake; and $\mathrm{CF}=$ alfalfa haylage/corn silage diet containing $14.9 \%$ chopped corn fodder, and offered for ad libitum intake.

${ }^{3}$ Contrasts: (1) control versus all diets containing diluting agents (EGH, WS, or CF); (2) nonsortable diluting agent (EGH) versus sortable diluting agents (WS or CF); (3) WS versus CF; (4) linear effect of observation time; (5) quadratic effect of observation time; and (6) cubic effect of observation time.

consumption of the TMR and may partially decouple sorting from mean whole-pen heifer performance. It remains unclear whether these trends would persist with additional crowding that is common within some commercial heifer-rearing operations.

\section{Heifer Behaviors}

Interactions of diet and observation time were observed for eating $(P<0.001)$ and lying $(P=0.003)$ activities, and these data are presented and discussed as interaction means (Table 8). At $1300 \mathrm{~h}$ (approximately $3 \mathrm{~h}$ postfeeding), a greater percentage of heifers offered diets diluted with low-energy forages were observed eating compared with the control diet (39.7 vs. $21.6 \%$; $P$ $<0.001$ ). Others have reported increased feeding time when low-energy forages are added to heifer diets for ad libitum (Greter et al., 2008) or restricted (Kitts et al., 2011) DMI. No difference $(P=0.609)$ was observed in the percentage of heifers eating at $1300 \mathrm{~h}$ for EGH compared with the sortable diets (WS and CF); however, a greater percentage of heifers were eating WS than $\mathrm{CF}$
(43.9 vs. $34.7 \% ; P=0.004)$. By $1700 \mathrm{~h}$, no differences $(P \geq 0.131)$ were detected among diets diluted with low-energy forages, but collectively, more heifers were found eating those diets than observed for control (28.3 vs. $18.0 \% ; P<0.001)$. At $2100 \mathrm{~h}$, more heifers were eating WS compared with CF (25.2 vs. $18.9 \% ; P=0.043)$, but no other contrasts were detected at 2100, 0100, and $0600 \mathrm{~h}(P \geq 0.087)$. The effects of eating behaviors also were reflected (inversely) in percentages of heifers lying in free stalls; at $1300 \mathrm{~h}$, more heifers offered the control diet were lying down compared with those diets containing low-energy forages (55.8 vs. $39.8 \%$; $P$ $<0.001$ ), and this difference also tended to persist at $1700 \mathrm{~h}(62.2$ vs. $55.6 \% ; P=0.051)$. The ANOVA for other heifer activities (Table 9) yielded no interactions of diet and observation time $(P \geq 0.364)$. Although significant contrasts of main-effect means were detected for all other activities, percentages of heifers involved in these activities were generally small $(\leq 8.8 \%)$ across all observation times, except for greater numbers standing inactively for the EGH diet (11.8\%), and at $1300 \mathrm{~h}$ $(11.6 \%)$ and $2100 \mathrm{~h}(17.3 \%)$. 


\section{CONCLUSIONS}

Inclusion of low-energy forages within blended alfalfa haylage/corn silage diets consumed by replacement dairy heifers was effective in reducing diet energy density and DMI. Our a priori hypothesis that EGH would be a nonsortable diluted diet, whereas $\mathrm{WS}$ and $\mathrm{CF}$ would be moderately and highly sortable, respectively, proved correct within the context of pef particles. However, sorting of forage particles by heifers could not be related to heifer performance. Average daily gains were reduced by dilution in all cases, but ADG were virtually identical between EGH and CF diets, which exhibited no sorting and extensive sorting of pef, respectively. Furthermore, ADG for WS was approximately $0.2 \mathrm{~kg} / \mathrm{d}$ less than EGH or CF, despite exhibiting sorting characteristics intermediate between EGH and CF.

\section{ACKNOWLEDGMENTS}

The authors gratefully acknowledge the assistance of USDA-Agricultural Research Service (Marshfield, WI) and University of Wisconsin Marshfield Agricultural Research Station staff for their assistance in completing this project. Funds were provided through USDA-ARS CRIS Project \#5090-12630-003-00D.

\section{REFERENCES}

AOAC (Association of Official Analytical Chemists). 1990. Official Methods of Analysis. 15th ed. AOAC, Arlington, VA.

AOAC International. 1998. Official Methods of Analysis. 16th ed. AOAC International, Arlington, VA.

Bates, L. S., M. Bender, and W. Jackson. 1981. Eastern gamagrass. Seed structure and protein quality. Cereal Chem. 58:138-141.

Coblentz, W. K., M. G. Bertram, P. C. Hoffman, N. M. Esser, and J. S. Cavadini. 2014. Fall harvest management of eastern gamagrass. Forage and Grazinglands http://dx.doi.org/10.2134/FG-20140016-RS.

Coblentz, W. K., P. C. Hoffman, N. M. Esser, and M. G. Bertram. 2012. Using eastern gamagrass to construct diets that limit intake and caloric density for dairy heifers. J. Dairy Sci. 95:6057-6071.

Coblentz, W. K., P. C. Hoffman, N. M. Esser, and M. G. Bertram. 2013. Technical note: Whole-pen assessments of nutrient excretion and digestibility from dairy replacement heifers housed in sandbedded freestalls. J. Anim. Sci. 91:4841-4848.

Coblentz, W. K., P. C. Hoffman, W. E. Jokela, and M. G. Bertram. $2010 \mathrm{~b}$. Unique dairy applications for eastern gamagrass in central Wisconsin: II. Nutritive value and energy density. Agron. J. 102:1720-1730.

Coblentz, W. K., W. E. Jokela, P. C. Hoffman, and M. G. Bertram. 2010a. Unique dairy applications for eastern gamagrass in central Wisconsin: I. Yield potential. Agron. J. 102:1710-1719.

Cook, N. B., T. B. Bennett, and K. V. Nordlund. 2004. Effect of free stall surface on daily activity patterns in dairy cows with relevance to lameness prevalence. J. Dairy Sci. 87:2912-2922.

DeVries, T. J., K. A. Beauchemin, and M. A. G. von Keyserlingk. 2007. Dietary forage concentration affects the feed sorting behavior of lactating cows. J. Dairy Sci. 90:5572-5579.

DeVries, T. J., F. Dohme, and K. A. Beauchemin. 2008. Repeated ruminal acidosis challenges in lactating dairy cows at high and low risk for developing acidosis: Feed sorting. J. Dairy Sci. 91:3958 3967.

DeVries, T. J., and M. A. G. von Keyserlingk. 2009. Competition for feed affects the feeding behavior of growing dairy heifers. J. Dairy Sci. 92:3922-3929.

Esser, N. M., P. C. Hoffman, W. K. Coblentz, M. W. Orth, and K. A. Weigel. 2009. The effect of dietary phosphorus on bone development in dairy heifers. J. Dairy Sci. 92:1741-1749.

Goering, H. K., and P. J. Van Soest. 1970. Pages 8-11 in Forage Fiber Analyses (Apparatus, Reagents, Procedures, and Some Applications). Agric. Handbook No. 379. USDA-ARS, Washington, DC.

Greter, A. M., T. J. DeVries, and M. A. G. von Keyserlingk. 2008. Nutrient intake and feeding behavior of growing dairy heifers: Effects of dietary dilution. J. Dairy Sci. 91:2786-2795.

Greter, A. M., K. E. Leslie, G. J. Mason, B. W. McBride, and T. J. DeVries. 2010. Effect of feed delivery method on the behavior and growth of dairy heifers. J. Dairy Sci. 93:1668-1676.

Greter, A. M., M. Prinsen, T. F. Duffield, B. W. McBride, T. M. Widowski, and T. J. DeVries. 2013. Growing heifers prefer supplementary long straw when fed a nutrient-dense ration. J. Dairy Sci. 96:3950-3958.

Hoffman, P. C. 1997. Optimum body size of Holstein replacement heifers. J. Anim. Sci. 75:836-845.

Hoffman, P. C., N. M. Brehm, S. G. Price, and A. Prill-Adams. 1996. Effect of accelerated postpubertal growth and early calving on lactation performance of primiparous Holstein heifers. J. Dairy Sci. 79:2024-2031.

Hoffman, P. C., C. R. Simson, and K. J. Shinners. 2006. Evaluation of hay feeding strategies on feed sorting behavior of dairy heifers fed mock lactation diets. J. Dairy Sci. 22:71-79.

Hoffman, P. C., C. R. Simson, and M. Wattiaux. 2007. Limit feeding of gravid Holstein heifers: effect on growth, manure nutrient excretion, and subsequent early lactation performance. J. Dairy Sci. 90:946-954.

Hoffman, P. C., K. A. Weigel, and R. M. Wernberg. 2008. Evaluation of equations to predict dry matter intake of dairy heifers. J. Dairy Sci. 91:3699-3709.

Jaster, E. H., and M. R. Murphy. 1983. Effects of varying particle size on digestion and chewing behavior of dairy heifers. J. Dairy Sci. $66: 802-810$.

Kitts, B. L., I. J. H. Duncan, B. W. McBride, and T. J. DeVries. 2011. Effect of the provision of a low-nutritive feedstuff on the behavior of dairy heifers limit fed a high-concentrate ration. J. Dairy Sci. 94:940-950.

Kononoff, P. J., A. J. Heinrichs, and D. R. Buckmaster. 2003. Modifications of Penn State forage and total mixed ration particle separator and the effects of moisture content on measurements. J. Dairy Sci. 86:1858-1863.

Kruse, K. A., D. K. Combs, N. M. Esser, W. K. Coblentz, and P. C. Hoffman. 2010. Evaluation of potential carryover effects associated with limit feeding gravid Holstein heifers. J. Dairy Sci. 93:5374-5384.

Lammers, B. P., A. J. Heinrichs, and R. S. Kensinger. 1999. The effects of accelerated growth rates and estrogen implants in prepubertal Holstein heifers on estimates of mammary development. J. Dairy Sci. 82:1753-1764

Lee, C., and A. N. Hristov. 2013. Short Communication: Evaluation of acid-insoluble ash and indigestible neutral detergent fiber as total-tract digestibility markers in dairy cows fed corn-silage based diets. J. Dairy Sci. 96:5295-5299.

Leonardi, C., and L. E. Armentano. 2003. Effect of quantity, quality, and length of alfalfa hay on selective consumption by dairy cows. J. Dairy Sci. 86:557-564.

Leonardi, C., and L. E. Armentano. 2007. Short communication: Feed selection by dairy cows fed individually in a tie-stall or as a group in a free-stall barn. J. Dairy Sci. 90:2386-2389.

Longenbach, J. I., A. J. Heinrichs, and R. E. Graves. 1999. Feed bunk length requirements for Holstein dairy heifers. J. Dairy Sci. 82:99109

NRC. 2001. Nutrient Requirements of Dairy Cattle. 7th rev. ed. National Academy Press, Washington, DC. 
Quigley, J. D. III, R. E. James, and M. L. McGilliard. 1986. Dry matter intake in dairy heifers. 1. Factors affecting intake of heifers under intensive management. J. Dairy Sci. 69:2855-2862.

Radcliff, R. P., M. J. Vandehaar, L. T. Chapin, T. E. Pilbeam, D. K. Beede, E. P. Stainisiewski, and H. A. Tucker. 2000. Effects of diet and injection of bovine somatotropin on prepubertal growth and first-lactation milk yields of Holstein cows. J. Dairy Sci. 83:23-29.

SAS Institute Inc. 2002. Version 9.2. SAS Institute Inc., Cary, NC.

Schulte, E. E., J. B. Peters, and P. R. Hodgson. 1987. Wisconsin procedures for soil testing, plant analysis and feed and forage analysis. Dept. Soil Sci. Bull. No. 6. University of Wisconsin, Madison.

Sejrsen, K., J. T. Huber, H. A. Tucker, and R. M. Akers. 1982. Influence of nutrition on mammary development in pre- and postpubertal heifers. J. Dairy Sci. 65:793-800.

Shaver, R. D., and P. C. Hoffman. 2010. Use of straw in dairy cattle diets. Focus on Forage. Vol. 12. No. 2. University of Wisconsin Extension, Madison.

St-Pierre, N. R. 2007. Design and analysis of pen studies in the animal sciences. J. Dairy Sci. 90(E. Suppl.):E87-E89.

Tomlinson, D. J., R. E. James, and M. L. McGilliard. 1991. Effect of varying levels of neutral detergent fiber and total digestible nutrients on intake and growth of Holstein heifers. J. Dairy Sci. 74:537-545.
Van Amburgh, M. E., D. M. Galton, D. E. Bauman, R. W. Everett, D. G. Fox, L. E. Chase, and H. N. Erb. 1998. Effects of three prepubertal body growth rates on performance of Holstein heifers during first lactation. J. Dairy Sci. 81:527-538.

Van Soest, P. J., J. B. Robertson, and B. A. Lewis. 1991. Methods for dietary fiber, neutral detergent fiber, and nonstarch polysaccharides in relation to animal nutrition. J. Dairy Sci. 74:3583-3597.

Waller, S. S., and J. K. Lewis. 1979. Occurrence of $\mathrm{C}_{3}$ and $\mathrm{C}_{4}$ photosynthetic pathways in North American grasses. J. Range Manage. 32:12-28.

Wildman, E. E., G. M. Jones, P. E. Wagner, R. L. Boman, H. F. Troutt Jr., and T. N. Lesch. 1982. A dairy cow body condition scoring system and its relationship to selected production characteristics. J. Dairy Sci. 65:495-501.

Zanton, G. I., and A. J. Heinrichs. 2007. The effects of controlled feeding of a high-forage or high-concentrate ration on heifer growth and first lactation milk production. J. Dairy Sci. 90:3388-3396.

Zanton, G. I., and A. J. Heinrichs. 2008. Rumen digestion and nutritional efficiency of dairy heifers limit-fed a high forage ration to four levels of dry matter intake. J. Dairy Sci. 91:3579-3588. 